\title{
Variações morfológicas em Edessa rufomarginata e revalidação de $E$. albomarginata e E. marginalis (Heteroptera, Pentatomidae, Edessinae) ${ }^{1}$
}

\author{
Eduardo José Ely e Silva², José Antonio Marin Fernandes³ \& Jocélia Grazia² \\ 1. Contribuição ${ }^{\circ} 425$ do Depto de Zoologia, Universidade Federal do Rio Grande do Sul (UFRGS). \\ 2. Depto de Zoologia, Instituto de Biociências, UFRGS, Av. Bento Gonçalves, 9500, Bloco IV, Prédio 43435, 91501-970 Porto \\ Alegre, RS, Brasil. \\ 3. Depto de Biologia, Centro de Ciências Biológicas, Universidade Federal do Pará, Rua Augusto Corrêa nº1, 66075-110 Guamá, \\ Belém, PA, Brasil.
}

\begin{abstract}
Morphological variants in Edessa rufomarginata and revalidation of E. albomarginata and $\boldsymbol{E}$. marginalis (Heteroptera, Pentatomidae, Edessinae). Based on the types of Edessa rufomarginata (De Geer, 1773 ) and its synonyms, on morphology of the paramere and coloration, seven patterns are described for $E$. rufomarginata. Pentatoma furcata Palisot de Beauvois, 1805, Cimex cruentus Fabricius, 1775, Aceratodes flavovirens Stål, 1855 and A. flavomarginatus Stål, 1855 are mantained as junior synonyms of E. rufomarginata. A. albomarginatus Stål, 1855 and A. marginalis Dallas, 1951 are removed from the synonymy of E. rufomarginata and are reinstated in Edessa. Aceratodes discolor Dallas, 1951 is removed from the synonymy of E. rufomarginata and is considered junior synonym of Edessa abdominalis Erichson, 1848.
\end{abstract}

KEYWORDS. Edessa rufomarginata, Edessinae, morphology, synonymy.

\section{INTRODUÇÃO}

De GeER (1773) descreveu Cimex rufomarginatus para a "América" e FABRICIUS (1775) acrescentou Cimex cruentus, do Suriname. Fabricius (1803) estabeleceu o gênero Edessa transferindo para este $C$. cruentus e várias outras espécies que ele mesmo havia proposto para Cimex. Palisot de Beauvois (1805) descreveu Pentatoma furcata como sendo da localidade de "d'Oware" no Benin, África. Este engano, provavelmente, ocorreu devido à mistura de exemplares de espécies coletadas na República Dominicana (América Central), com as coletadas no Benin, uma vez que a subfamília Edessinae é composta exclusivamente por espécies neotropicais. Амүот \& SERVILLE (1843) propuseram o gênero Aceratodes para incluir Edessa cruenta (Fabricius, 1775). Dallas (1851) descreveu Aceratodes marginalis da América do Sul com base em uma fêmea e Aceratodes discolor da Guiana Inglesa, baseado em um macho. STÅL (1855) descreveu Aceratodes flavovirens, A. albomarginatus e A. flavomarginatus com base em três exemplares procedentes de Minas Gerais. WALKER (1867) sinonimizou Pentatoma furcata com A. cruentus.

STÅL (1872) considerou Aceratodes subgênero de Edessa e transferiu Cimex rufomarginatus para este gênero. Propôs, como sinônimos-júnior de $E$. rufomarginata, A. cruentus e A. discolor. Reconheceu ainda três variedades: variedade 1, ilustrada por STOLL (1788); variedade 2 , representada pelos exemplares anteriormente descritos como A. marginalis, A. albomarginatus e A. flavomarginatus e variedade 3, representada pelo exemplar anteriormente descrito como A. flavovirens.

Distant (1881), Lethierry \& Severin (1893) e KIRKALDY (1909) praticamente acompanharam a proposta de STÅL (1872), na sinonimia de E. rufomarginata, com exceção do status da variedade 1 que LETHIERRY \& SEVERIN
(1893) omitem e KIRKALDY (1909) nomeia como sendo "var.(b) aruakana nov."

Edessa rufomarginata possui ampla distribuição, ocorrendo do México até a Argentina (KIRKALDY, 1909). É citada alimentando-se de inúmeras plantas da família Solanaceae (Buckup, 1961; Bertels, 1962; Silva et al., 1968; Rizzo \& SAINI, 1987) incluindo plantas cultivadas como fumo, beringela, batata e tomate, além de algodão (Malvaceae) (Monte, 1939; Biezanko et al., 1949; Ruffinelli \& CARBOnEL, 1953; Rizzo \& SAINI, 1987).

Esta espécie apresenta polimorfismo que dificulta sua identificação e podem ocorrer determinações errôneas. O objetivo é analisar as variações morfológicas, em especial da genitália dos machos, visando reconhecer e estabelecer os limites de E. rufomarginata e reavaliar o "status" das espécies a ela sinonimizadas.

\section{MATERIAL E MÉTODOS}

Foram examinados 231 exemplares (incluindo os holótipos) pertencentes às seguintes coleções: Carnegie Museum of Natural History, Pittsburg, EUA (CMNH); Departamento de Zoologia, Universidade Estadual de Campinas, Campinas, SP, Brasil (ZUEC); Departamento de Zoologia, Universidade Federal do Rio Grande do Sul, Porto Alegre, RS, Brasil (UFRG); Instituto Agronômico, Campinas, SP, Brasil (IACC); Instituto Biológico, São Paulo, SP, Brasil (IBSP); Instituto Nacional de Pesquisas da Amazônia, Manaus, AM, Brasil (INPA); Laboratório de Zoologia, Universidade do Amazonas, Manaus, AM, Brasil (DCMB); Museo Argentino de Ciencias Naturales "Bernardino Rivadavia", Buenos Aires, Argentina (MACN); Museo del Instituto de Zoologia Agrícola, Maracay, Venezuela (MIZA); Museu de Zoologia, Universidade de São Paulo, São Paulo, SP, Brasil (MZSP); Museu Nacional, Universidade Federal do Rio de Janeiro, Rio de Janeiro, RJ, Brasil (MNRJ); Museu Paraense Emílio 
Goeldi, Belém, PA, Brasil (MPEG); Museum für Naturkunde, Berlin, Alemanha (ZMHB); Nationaal Natuurhistorische Museum, Leiden, Holanda (RMNH); Naturhistoriska Riksmuseet, Estocolmo, Suécia (NHRM); The Natural History Museum, London, Inglaterra (BMNH); Universidad Nacional de Tucumán, Fundacion y Instituto Miguel Lillo, Tucumán, Argentina (IMLA).

Foram dissecados os pigóforos de 15 machos de E. rufomarginata para análise da variação morfológica dos parâmeros. A terminologia adotada para as peças genitais segue DupuIs (1970).

\section{Edessa rufomarginata (De Geer, 1773) (Figs. 1-12)}

Cimex rufomarginatus DE GEeR, 1773:330; STÅL, 1872:57. Cimex cruentus Fabricius, 1775:713; FABriciUs, 1803:153. Edessa cruenta; FABricius, 1803:153; Burmeister, 1835:355; АмYот \& Serville, 1843:160.

Pentatoma furcata Palisot de Beauvois, 1805:46; Walker, 1867:451. Aceratodes cruentus; Amyot \& SeRville, 1843:160; Dallas, 1851:334; WALKER, 1867:451; STÅL, 1872:57.

Aceratodes flavomarginatus STÅL, 1855:183; STÅL, 1872:57. Aceratodes flavovirens STÅL, 1855:183; STÅL, 1872:57.

Edessa rufomarginata; STÅL, 1872:57; Distant, 1880:96; SHARP, 1890:410; Lethierry \& SEVERIN, 1893:194; KirKaldy, 1909:164; Buckup, 1961:10; Silva et al., 1968:60; GraZia-VieIRA \& CASINI, 1973:59; Froeschner, 1981:66; Rizzo \& SAINI, 1987:51; Fortes \& GraZIA, 1990:191.

Diagnose. Rostro com o primeiro segmento mais longo que as búculas; cabeça do parâmero com duas projeções, uma dirigida anteriormente, alongada, com ápice arredondado e uma posterior, retangular; face externa da cabeça do parâmero apresentando uma área sulcada; processo da taça genital retangular, achatado lateralmente, fendido medianamente e encoberto parcialmente pelo parâmero; décimo segmento com margem posterior projetada; gonocoxito 8 não deprimido possuindo o bordo posterior em arco aberto.

Descrição da forma I. Comprimento 14,7-20,7 mm; largura 8,9-12,2 mm; corpo ovalado. Coloração geral da face dorsal verde; margens das jugas, margens ânterolaterais do pronoto, margem do terço anterior do cório e conexivo avermelhados; pontuação fina, da mesma cor que a superfície. Ângulos umerais não desenvolvidos. Face ventral, pernas e antenas alaranjadas, com estrias negras nas áreas intersegmentares do tórax e abdome, nas pseudo-suturas e posteriormente aos espiráculos.

Cabeça mais larga que longa. Jugas mais longas que o clípeo, com pequenos sulcos transversais e sem pontuação, arredondadas e curvadas ventralmente no ápice. Tubérculos anteníferos com dente reduzido; antenômeros 1 a 5 em ordem crescente de comprimento. Rostro atingindo a primeira bifurcação do processo do metasterno, com o primeiro segmento mais longo que as búculas. Búculas paralelas e largas. Pronoto declivente, brilhante, com os ângulos ântero-laterais armados com um pequeno dente. Margem ântero-lateral reta, íntegra e levemente emarginada. Cicatrizes do pronoto subcalosas e não pontuadas. Superfície ventral do pronoto com pontuação fina clara ou escura. Escutelo brilhante com ápice levemente acuminado. Cório fosco, com pontuação mais fina e densa do que a do resto do corpo e veias sem diferença de tonalidade. Membrana do hemiélitro castanho-escura a negra, freqüentemente com reflexo verde-metálico. Mesosterno com uma carena mediana baixa que avança até as coxas anteriores. Processo metasternal mais longo que largo, achatado, liso e glabro, com a bifurcação anterior divergente e os ápices evanescentes. Bifurcação anterior do processo metasternal atingindo o terço mediano do mesosterno, acomodando o quarto e parte do terceiro segmento do rostro. Área evaporatória rugosa, fosca e da mesma cor da face ventral; peritrema ostiolar atingindo $4 / 5$ da largura
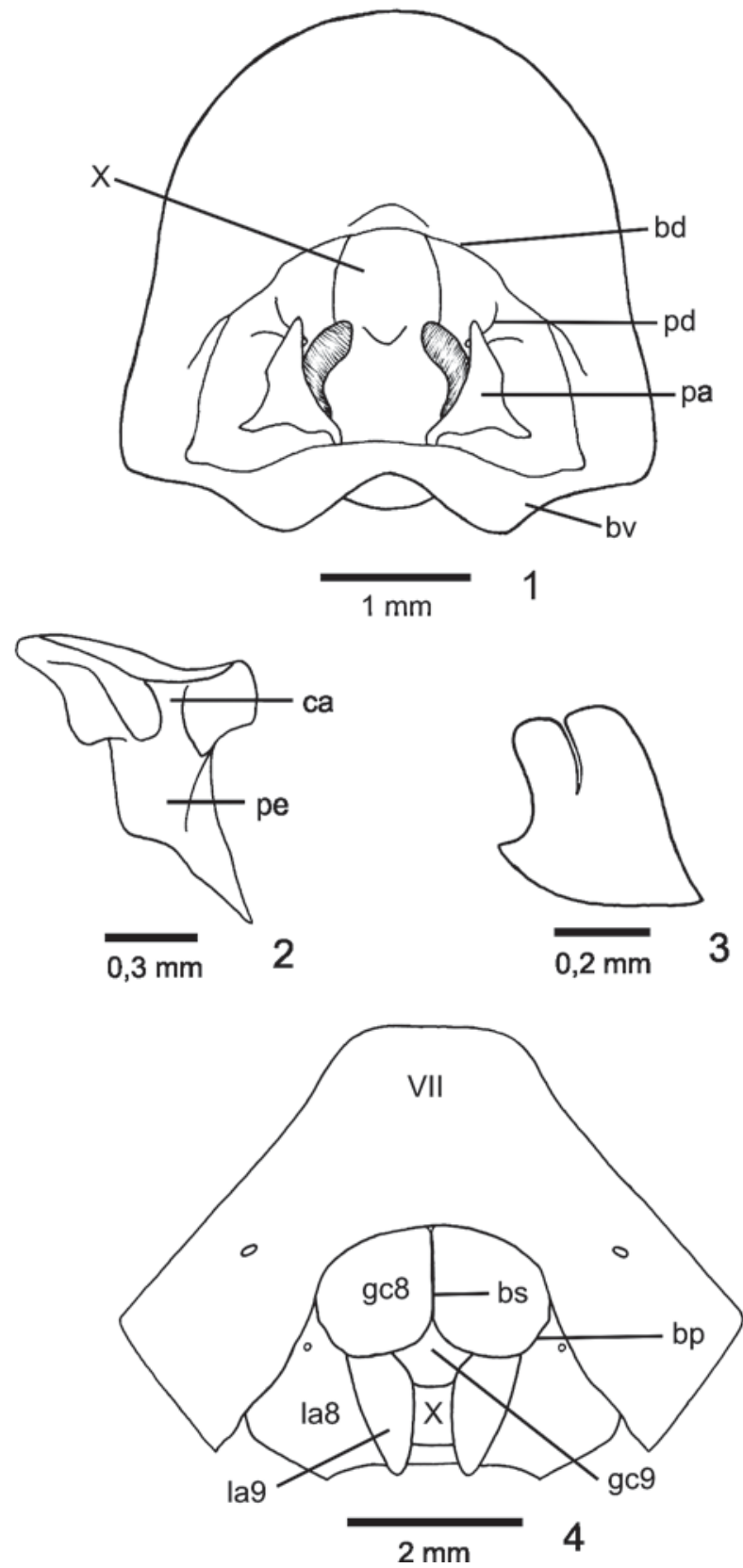

Figs. 1-4. Edessa rufomarginata (De Geer, 1773): 1, pigóforo, vista dorso-posterior; 2, parâmero, vista lateral externa; 3, processo da taça genital, vista lateral; 4, placas genitais, vista ventral (bd, bordo dorsal; bp, bordo posterior; bs, bordo sutural; bv, bordo ventral; ca, cabeça; gc8, gonocoxito 8; gc9, gonocoxitos 9; la8, laterotergito 8; la9, laterotergito 9; pa, parâmero; pd, processo da taça genital; pe, pé; VII, $7^{\circ}$ segmento abdominal; X, $10^{\circ}$ segmento abdominal). 
da metapleura. Abdome com conexivo exposto e pontuação fina, densa, da mesma cor da superfície dorsal. Ângulos póstero-laterais do conexivo pouco desenvolvidos. Ângulos posteriores do sétimo segmento moderadamente desenvolvidos. Face dorsal do abdome preta, brilhante; superfície ventral com pontuação fina e esparsa. Espiráculos elípticos e tricobótrios na mesma linha dos espiráculos.

Genitália do macho. Pigóforo retangular em vista dorsal, com abertura dorso-posterior e ângulos pósterolaterais arredondados (fig. 1); superfície ventral com pontuações e sulcos sinuosos na metade posterior. Cabeça do parâmero com duas projeções, uma dirigida anteriormente, alongada, com ápice arredondado e uma posterior, retangular, podendo apresentar algumas variações nas proporções nas diferentes formas (figs. 2, 5-12). Face externa da cabeça do parâmero com uma área sulcada e esculturação variada (figs. 2, 5-12); face superior côncava. Processo da taça genital retangular, achatado lateralmente, fendido medianamente (fig. 3) e encoberto parcialmente pelo parâmero. Décimo segmento com margem posterior projetada, sulcada e recoberta por pêlos; face posterior truncada e sem carenas (fig. 1).

Genitália da fêmea. Gonocoxitos 8 pilosos, pontuados e em plano diferente das demais placas genitais. Bordo posterior do gonocoxito 8 formando um arco aberto. Gonocoxitos 9 pilosos, de formato trapezoidal e fracamente convexo, sem carena mediana (fig. 4).

Distribuição. México a Argentina.

Variação. Devido ao seu polimorfismo, E. rufomarginata apresenta outras seis formas, que podem ser diferenciadas da forma I, a de ocorrência mais comum, pelas característícas abaixo mencionadas.

Forma II. Comprimento 14,5-18,9 mm; largura 8,1$10,9 \mathrm{~mm}$. Coloração geral da face dorsal castanha; membrana do hemiélitro castanho-clara brilhante; margens das jugas, margens ântero-laterais do pronoto e bordas laterais do cório amareladas a creme. Escutelo levemente rugoso com estrias transversais. Face dorsal do abdome castanha. Face ventral, pernas e antenas castanhas a castanho-alaranjadas; estrias negras restritas ao limite dos segmentos abdominais e posteriormente aos espiráculos, sendo algumas vezes ausentes. Processo metasternal sulcado.

Distribuição. Brasil: Minas Gerais e São Paulo.

Forma III: comprimento 14,8-16,9 mm; largura 8,510,3 mm. Coloração dorsal verde-clara com pontuação amarelada; membrana do hemiélitro transparente, castanho-clara a amarela. Margens das jugas, margens ântero-laterais do pronoto, terço anterior do cório e conexivo amareladas a creme. Bifurcação anterior do processo metasternal acomodando o terceiro e o quarto segmentos do rostro; processo metasternal sulcado. Abdome dorsalmente negro, algumas vezes com manchas amareladas. Face ventral, pernas e antenas amareladas a creme. Estrias negras ausentes. Superfície ventral do pigóforo na metade posterior com pontuações e sem sulcos. Gerais.

Distribuição. Brasil: Goiás, Mato Grosso e Minas

Forma IV: comprimento 17,9-20,6 mm; largura 10,7$11,7 \mathrm{~mm}$. Coloração geral negra nas faces dorsal e ventral.
Margens das jugas, margens ântero-laterais do pronoto, borda do terço anterior do cório, conexivo, pernas e antenas laranja-escuras a vermelhas. Comprimento do segundo e terceiro antenômeros subigual. Dente dos ângulos ânteros-laterais do pronoto muito reduzido.

Distribuição. Venezuela.

Forma V: comprimento 16,6-18,4 mm; largura 10,2$10,7 \mathrm{~mm}$. Coloração dorsal verde-oliva a verde-escura, membrana do hemiélitro verde-escura metálica. Margens das jugas, margens ântero-laterais do pronoto, conexivo e terço anterior da borda do cório vermelhos. Rostro mais longo que nas outras formas, alcançando as coxas do
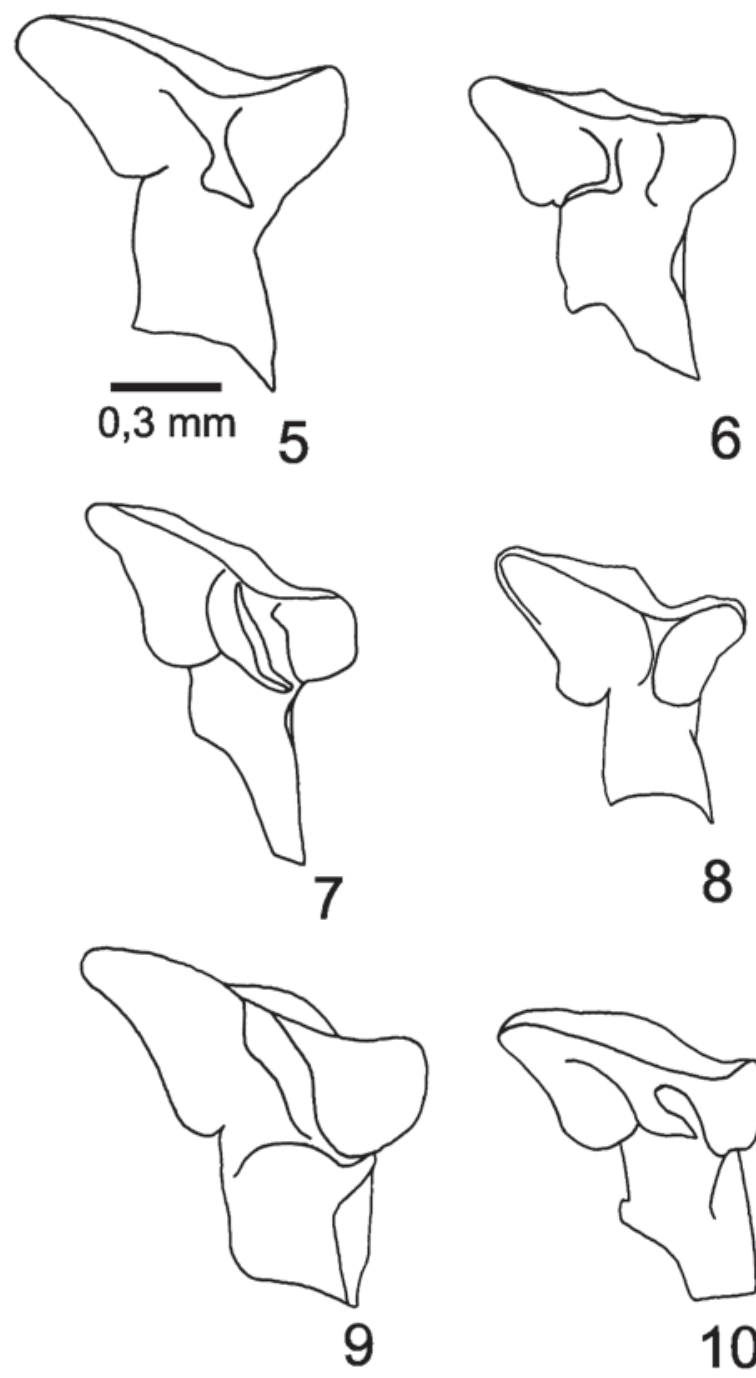

8
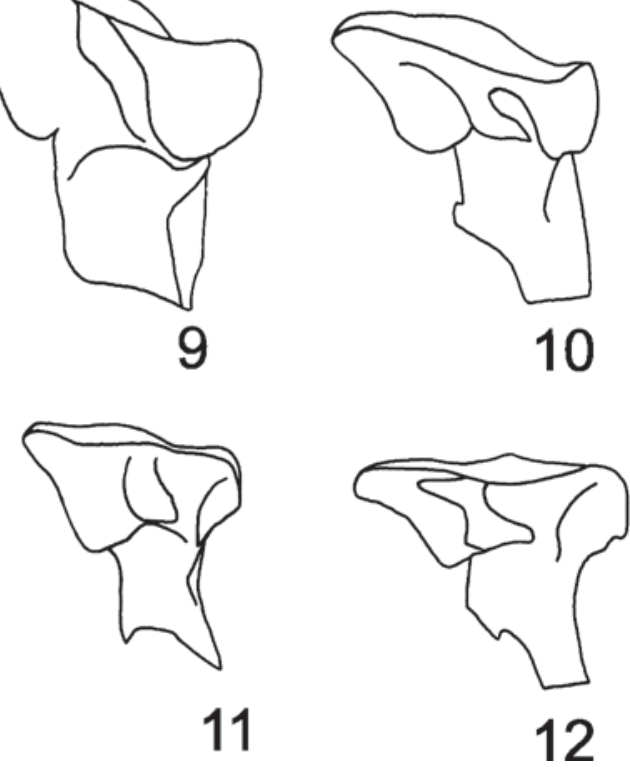

Figs. 5-12. Edessa rufomarginata (De Geer, 1773): variação dos parâmeros, vista lateral externa; 5, 6, forma I; 7, forma II; 8, forma III; 9, forma IV; 10, forma V; 11, forma VI; 12, forma VII. 
terceiro par de pernas. Face ventral, pernas e antenas alaranjadas; estrias negras nos limites dos segmentos abdominais e posteriormente aos espiráculos.

Distribuição. Brasil: Goiás.

Forma VI: comprimento 14,6-15,7 mm; largura 9,29,7 mm. Coloração dorsal verde-clara, membrana do hemiélitro castanha brilhante. Margens das jugas, margens ântero-laterais do pronoto, terço anterior da borda do cório e borda do ápice do escutelo creme. Primeiro antenômero menor que o segundo, segundo e terceiro subiguais, quarto maior que o terceiro e quinto maior que o quarto. Bifurcação anterior do processo metasternal acomodando apenas o quarto segmento do rostro. Face ventral, pernas, antenas e conexivo amarelos a laranja-claros; estrias negras ausentes.

Distribuição. Argentina: Córdoba e Salta.

Forma VII: comprimento 17,5-19,3 mm; largura 9,9$11,3 \mathrm{~mm}$. Face dorsal, em sua maior parte, verde-escura e membrana do hemiélitro negra, translúcida. Terço posterior da cabeça, margens das jugas, margens anterior e ântero-laterais do pronoto, terço anterior da borda do cório e terço anterior do escutelo amarelados. Bifurcação anterior do processo metasternal acomodando apenas o quarto segmento do rostro. Face ventral amarelada, pernas e antenas laranja-claras; estrias negras nos limites dos segmentos torácicos e abdominais e posteriormente aos espiráculos.

Distribuição. Argentina: Misiones.

Chave para as formas de E. rufomarginata.

1. Processo metasternal sulcado 2

Processo metasternal sem sulco ......................... 3

2(1). Coloração dorsal, incluindo a do abdome, castanha; escutelo levemente rugoso e com estrias transversais forma II

Coloração dorsal verde-clara com pontuações amareladas; abdome dorsalmente negro, algumas vezes com manchas amareladas .......... forma III

3(1). Rostro alcançando as coxas do terceiro par de pernas forma $\mathrm{V}$

Rostro não atingindo o terceiro par de pernas .... 4

4(3). Faces dorsal e ventral de coloração negra

forma IV

Faces dorsal e ventral de outra coloração

5(4). Coloração amarelada no terço posterior da cabeça, terço anterior da borda do cório e terço anterior do escutelo forma VII

Outra coloração

6(5). Face ventral com estrias negras nas áreas intersegmentares do tórax e abdome, nas pseudo-suturas e posteriormente aos espiráculos; borda do ápice do escutelo sem diferença de coloração forma I

Face ventral sem estrias negras; borda do ápice do escutelo creme forma VI

Material examinado. Cimex rufomarginatus, holótipo $\sigma^{*}$ "Surinam" (NHRM). Aceratodes flavomarginatus, holótipo $\&$, Minas Gerais, Brasil (NHRM). Aceratodes flavovirens, holótipo §. Minas Gerais, Brasil (NHRM). MÉXICO, Campeche: Carretera Campeche-Mérida km 54, ơ, 28.IV.1982, V. Meléndez col. (RMNH). VENEZUELA, Los Corales, ơ, \&, 1939 (MACN); Distrito Federal: Petaquire, El Junquito, \&, 21.VI.1964, E. Osuna col. (MIZA); Caracas, \&, 21.V.1950, C. Prado col. (MIZA);
Trujillo: Bocono, ơ, 13.VIII.1964, E. Osuna \& M. Gelbes col (MIZA); Carretera La Puerta-Vila Mercedes, Km 14, $q$, 21.IX.1954, C. Rosales col. (MIZA); Aragua: Colonia Tovar, 14.VII.1954, R. Salinas \& C. Rosales col. (MIZA); El Limón, 20.X.1954, C. Rosales col. (MIZA); \&, 08.IX.1963, A. Perez col. (MIZA); đ, 05.VIII.1966, C. Rodriguez col. (MIZA); Maracay \&, 29.X.1961, B. Fernandes col. (MIZA); Rancho Grande, 3 21.V.1966, F. Romero col. (MIZA); Zulia: Sierra de Perijá

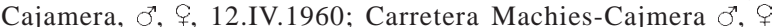
14.IV.1960 (UFRG); Mérida: La Mucuy, \&, 09.IX.1956, C. Rosales col.; Táchira: Pregonero, 2 o, 2 \&, 21.X.1966, C. Rosales \& J Salcedo col.; Barinas: Carretera Barinas-Apartaderos, $\sigma$, 10.V.1953, F. Kern col.; Bolívar: Caravachi, 2 o, 16.XI.1966, J e B. Bechyné \& E. Osuna col. (MIZA). SURINAME, Yungas Chuluani, O', I.1948, Bridarolli col. (UFRG). PERU, Cuzco Limatambo, f, 30.X.1964 (UFRG). BOLÍVIA: o', 2 क, 10.III.1924 Cochabamba: Prov. Chapare, Cristal Mayo,, II.1971, Fritz col. (MACN). BRASIL, Roraima: Rio Uraricoera, Ilha de Maracá, đ’, 2 (INPA); Amapá: Porto Platon, 4 ơ, 5 ‡, 14.IV.1983, J. Lacerda col. (UFRG); Amazonas: Coari, Rio Urucu $f$, 19.II01.III.1993, P. Bührnheim col. (DCMB); Guajara, Rio Ipixuna, \&, VI.1995, P. Bührnheim col. (DCMB); Manaus (Estrada AM 01, Km 64), of, \&, 08.VIII.1970, A. Faustino col. (INPA); (Santa Etelvina), of, 16.IV.1988, M. Amorim col. (INPA); (Conjunto Tiradentes), F, 20.IX.1984, E. Fernandes col. (INPA); Rio Tapajós, đ̆, XI.1960, Vollmann col. (RMNH) (comparado com o holótipo de E. rufomarginata); Pará: Belém, \&, 12.II.1984, J. Grazia col. (UFRG); Cachoeira do Arari, \&, 21.VII.1983, A Henriques col. (INPA); Porto Trombetas, \&, 07.IV.1983, Grazia \& Pires col. (UFRG); Tucuruí, ơ, I.1979, M. Alvarenga col (UFRG); Mato Grosso: Chapada [dos Guimarães], $15^{\circ} 26^{\prime} \mathrm{S}$ e $55^{\circ} 45^{\prime} \mathrm{W}$, o' $^{\circ}$, $1882-1884$, H. Smith col. (CMNH); Chapada dos Guimarães, o, 4 \&, 16.II.2000, J. Grazia col. (UFRG); Barra do Tapirapé, o, 14.XII.1964, B. Malkin col. (MZSP); Utiariti, Rio Papagaio, \&, VII-VIII.1961, K. Lenko col. (MZSP); ठ', 22 31.X.1966, Lenko e Pereira col. (MZSP); Pernambuco: João Alfredo, 3 o, 05.IV.2001, M. Lopes col. (UFRG); Lagoa do Carro, 7 §., 4 \&, 05.IV.2001, M. Lopes col. (UFRG); Posto Gran, Via São Lourenço, ơ, 5 \&, 05.IV.2001, M. Lopes col. (UFRG); Bahia: Cruz das Almas, 2 \&, 05.V.1997, W. Sá col. (UFRG); Goiás: Alto Paraíso, 2 ơ, 2 \&, 11.X.1999, A. Faria col. (IBSP); Campinas, \&, XII.1935, Spitz col. (MZSP); Jataí, $\varsubsetneqq$, (UFRG); (Fazenda Cachoeirinha), $q$ X.1962 (MZSP); Minas Gerais: Belo Horizonte, $\subsetneq$, Monte col. (MZSP); đ', 08.VII.1942, A. Costa col. (IBSP); Japonar, ひ', 2 甲, 20.VIII.2000 (UFRG); Lagoa Santa, ơ, \&, 09.X.1958, J. Becker col. (MNRJ) (comparados com o holótipo de A. flavovirens) Uberlândia, \&, X.1962 (MZSP); Espírito Santo: Santa Teresa, o, §, VIII.1992, A. Oliveira col.; Rio de Janeiro: Rio de Janeiro (Parque da Cidade), 2 \& 02.XI.1956, R. Thomaz col. (UFRG), São Paulo: São João da Boa Vista, $\varsubsetneqq$, XII.1935, B. Ribeiro col (IBSP); São José dos Campos, $\varsubsetneqq$, IV.1935, L. Vieira col. (IBSP); São Sebastião (Sertão do Camburi), O', 09.IX.1995, N. Peixoto col. (IBSP); Pirassununga, ơ, 24.VIII.1976, L. Fontes col. (MZSP); (Fazenda Graciosa), O', \&, 16.X.1945, Schubart col. (IBSP); Limeira, \&, 05.XII.1953, (IBSP); Campinas, Ő, 2 \&, Rossetto col (IACC); శ', , X, XI.1987 (IACC); Mogi Guaçu (Fazenda Capininha), 2 ơ, \&, 17-19.XI.1967, H. Reichardt col. (MZSP); Luíz Antonio (Estação Ecológica de Jataí), \&, 02.XI.1993, N. Peixoto col. (IBSP); Itirapina, 2 శ', 3 \&, 20.II.1984, P. Oliveira col. (UFRG); Teodoro Sampaio, đ’, XI.1977, M. Alvarenga col. (UFRG); Rio Grande do Sul: Derrubadas (Parque Estadual do Turvo), $\$$, 21 25.V.1984, S. Bonatto col. (UFRG); Porto Alegre, o, 19.IX.1983, S. Bonato col. (UFRG); Guaíba, 3 \%, 2 \&, IV.1988, N. Fortes col. (UFRG); 4 ơ, 3 \&, X.1988, N. Fortes col. (UFRG); Encruzilhada do Sul, of, क, 10.X.1992, L. Campos col. (UFRG). ARGENTINA, Jujuy: 2 (MACN); Rio Grande, $\subsetneq(\mathrm{MACN})$; Salta: San Ramón de Nueva Orán, ơ (MACN); Pocitos, ơ, XII.1971, Fritz col. (MACN); đ, 2 \&, I.1972, Fritz col. (MACN); Misiones: Parque Nacional Iguazú, 3 ơ, 3 \&, X.1977, H. Pepe col. (MACN); Iguazú, \&, 1946 (MACN); Posadas, o (MACN); Santa Maria, \&, M. Viana col. (MACN); Estação Experimental Loreto, ơ, A. Ogloblin col (MACN); Corrientes: Mercedes, ơ, II.1974, M. Viana col (MACN); Córdoba: Dep. de Calemuchita, El Sauce, \&, XII.1938, M. Viana col. (MACN); Entre Ríos: Concordia, \&, I.1979, M Viana col. (MACN); Departamento de Colon, \&, II.1990, D. Rider 
col. (UFRG); Mendoza: Cacheuta, 2 హ, 2 \&, 07.VIII.1944 (MACN); Buenos Aires: Rosas, $\subsetneq$, J. Daguerre col. (MACN); Buenos Aires, ơ, 08.I.1898, S. Venturi col. (MACN); 2 \&, 20.II.1899, S. Venturi col. (MACN); \&, 15.III.1904, A. Zotta col. (MACN); §, XI.1945, Aloisi col. (MACN); ð, \&, 16.X.1946, Píran col. (MACN); Martin Garcia, \&, 1935, J. Daguerre col. (MACN). URUGUAI, Montevidéo: Montevidéo, 2 ơ, \&, H. Parker col. (IACC); đ̛, \&, 26.IV.1918, Felippone col. (MACN).

\section{Edessa albomarginata (Stål, 1855) revalidada (Figs. 13-16)}

Aceratodes albomarginatus STÅL, 1855:183; WALKER, 1867:453. Edessa (Aceratodes) albomarginata; STÅL, 1872:57.

Diagnose. Rostro com o primeiro segmento tão longo quanto as búculas; superfície ventral do abdome com pontuação fina e esparsa; bordo dorsal do pigóforo com duas abas que se projetam de cada lado sobre as laterais do décimo segmento, encobrindo os processos do diafragma; cabeça do parâmero com duas projeções, uma anterior alongada e afilada e uma posterior curta e retangular; face externa da cabeça do parâmero com uma depressão; processo da taça genital de contorno retangular, com sutura diagonal junto ao ápice, que acompanha uma leve reentrância e outra sutura basal sem reentrância; décimo segmento com margem posterior não projetada; gonocoxito 8 com o terço posterior deprimido e bordo posterior formando um arco fechado e recortado próximo ao bordo interno.

Descrição. Comprimento 13,8-17,3 mm; largura 8,3$10,5 \mathrm{~mm}$, corpo ovalado. Coloração dorsal castanha a verde-oliva; margens das jugas, margens ântero-laterais do pronoto e dois terços das bordas do cório de coloração branco-amarelada. Superfície dorsal com pontuação escura, exceto conexivo onde a pontuação é clara. Ângulos umerais não desenvolvidos. Face ventral, pernas e antenas de coloração castanha mais clara que a face dorsal; estrias negras do abdome ausentes ou reduzidas, localizadas próximo à margem do abdome.

Cabeça mais larga que longa. Jugas mais longas que o clípeo, com pequenos sulcos transversais e sem pontuação, arredondadas e curvadas ventralmente no ápice. Tubérculos anteníferos com dente reduzido; primeiro antenômero mais curto que o segundo, segundo e terceiro subiguais, quarto mais longo que o terceiro e quinto mais longo que o quarto. Rostro atingindo a primeira bifurcação do processo do metasterno, com o primeiro segmento tão longo quanto as búculas. Búculas paralelas e largas. Pronoto declivente, brilhante, com os ângulos ântero-laterais armados com pequeno dente; margem ântero-lateral reta, íntegra e levemente emarginada; cicatrizes do pronoto subcalosas e não pontuadas. Superfície ventral do pronoto com pontuação igual a da superfície dorsal. Escutelo brilhante com ápice levemente acuminado. Cório fosco, com pontuação igual a do resto do corpo e veias sem diferença de coloração. Membrana do hemiélitro castanho-escura a negra, brilhante, sem reflexo metálico. Mesosterno com carena mediana baixa que avança até as coxas anteriores. Processo metasternal mais longo que largo, achatado, liso e glabro, com a bifurcação anterior divergente e ápices evanescentes. Bifurcação anterior do processo metasternal atingindo o meio do mesosterno e acomodando parcialmente o quarto segmento do rostro.
Área evaporatória rugosa, fosca, mais clara que a face ventral; peritrema ostiolar atingindo $4 / 5$ da largura da metapleura. Conexivo exposto, com a pontuação fina, densa, da mesma cor que a da face dorsal. Ângulos póstero-laterais do conexivo pouco desenvolvidos.
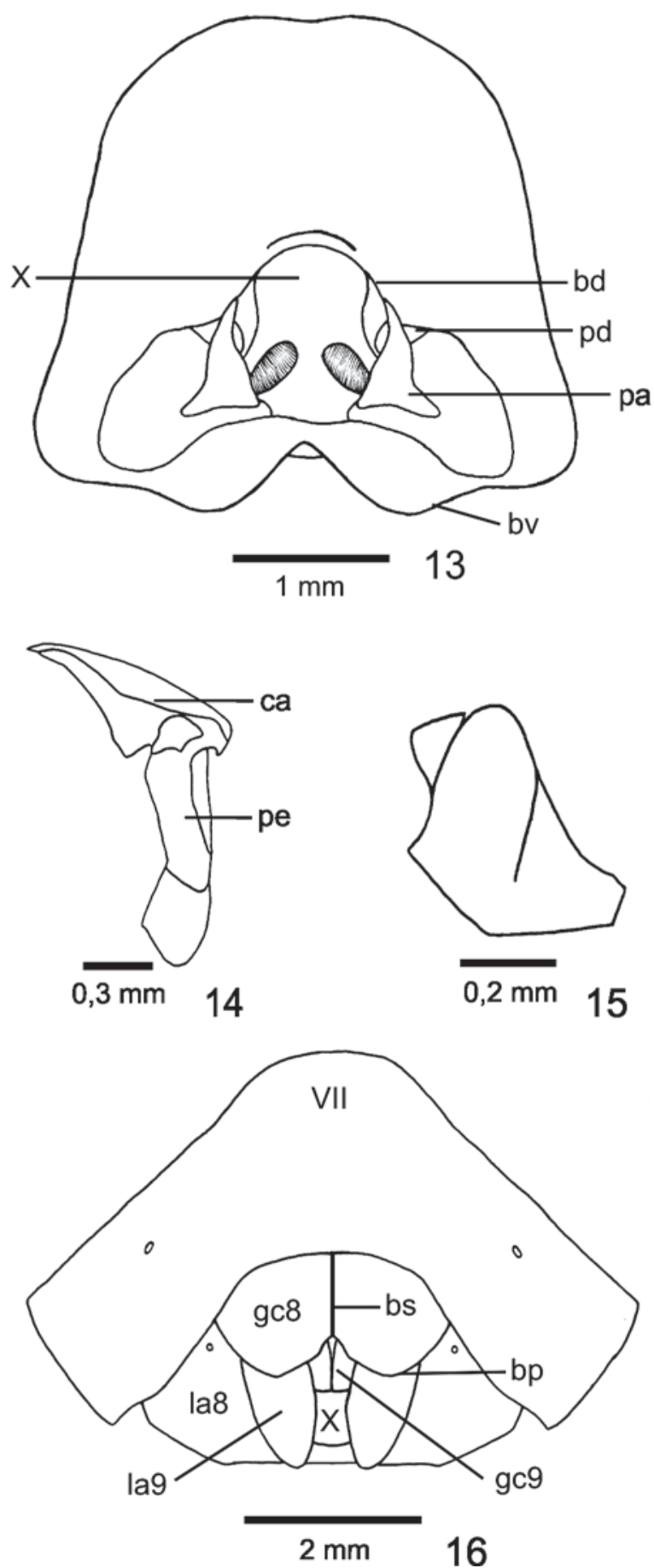

Figs. 13-16. Edessa albomarginata (Stål, 1855): 13, pigóforo, vista dorso-posterior; 14, parâmero, vista lateral externa; 15, processo da taça genital, vista lateral; 16, placas genitais, vista ventral (bd, bordo dorsal; bp, bordo posterior; bs, bordo sutural; bv, bordo ventral; ca, cabeça; gc8, gonocoxito 8; gc9, gonocoxitos 9; la8, laterotergito 8; la9, laterotergito 9; pa, parâmero; pd, processo da taça genital; pe, pé; VII, $7^{\circ}$ segmento abdominal; $\mathrm{X}$, $10^{\circ}$ segmento abdominal). 
Ângulos posteriores do sétimo segmento pouco desenvolvidos. Face dorsal do abdome castanha a verdeoliva; superfície ventral com pontuação fina e esparsa. Espiráculos elípticos e tricobótrios na mesma linha dos espiráculos.

Genitália do macho. Pigóforo retangular em vista dorsal, com abertura dorso-posterior e ângulos pósterolaterais arredondados; superfície ventral pontuada no terço posterior. Bordo dorsal do pigóforo com duas abas que se projetam de cada lado sobre as laterais do décimo segmento, encobrindo os processos da taça genital (fig. 13). Cabeça do parâmero com duas projeções, uma anterior muito alongada e afilada e uma posterior, curta e retangular. Face externa da cabeça do parâmero com uma depressão junto do pé do parâmero (fig. 14). Processo da taça genital de contorno retangular, com sutura diagonal junto ao ápice, que acompanha uma leve reentrância e outra sutura basal, sem reentrância (fig. 15). Décimo segmento cilíndrico, com margem posterior não projetada, sulcada e recoberta por pêlos; face posterior truncada, com sulco e sem carenas (fig. 13).

Genitália da fêmea. Gonocoxitos 8 pilosos, pontuados, em um plano diferente das demais placas genitais e com o terço posterior deprimido; bordo posterior do gonocoxito 8 formando um arco fechado e recortado próximo ao bordo interno. Gonocoxitos 9 pilosos, formato trapezoidal e fortemente convexo, freqüentemente com carena mediana (fig. 16).

Distribuição. Brasil e Argentina.

Material examinado. BRASIL, Minas Gerais: holótipo, q (NHRM); São Paulo: Itu, O', XI.1958, D. Martins col.(MZSP); George Oeterer, ơ' 15.X.1961, Werner col. (MZSP); Rio Grande do Sul: Barra do Quaraí (Parque Estadual do Espinilho), హ゙, q, 18.IX.2003, C. Schwertner col. (UFRG). ARGENTINA, Jujuy:

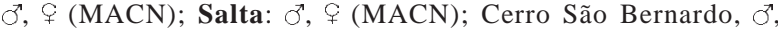
I.1954, F. Monrós col. (IMLA) (comparado com o holótipo de A. albomarginatus); Chaco: $̋$, $\subsetneq(\mathrm{MACN})$; Tucumán: (MACN); Entre Ríos: Concordia, ơ, I.1979, M. Viana col. (MACN); Federal (El Monte), 2 o, 2 \&, 20.VII.1966, A. Pirán col. (MACN); đ, f, 20.VII.1966, A. Pirán col. (MACN); Mendoza: Cacheuta, $q(\mathrm{MACN})$; Buenos Aires: $\sigma$ (MACN).

\section{Edessa marginalis (Dallas, 1851) revalidada} (Figs. 17-20)

Aceratodes marginalis DALLAS, 1851:335; WALKER, 1867:453. Edessa (Aceratodes) marginalis; STÅL, 1872:57.

Diagnose. Rostro com o primeiro segmento tão longo quanto as búculas; mesosterno sem carena mediana e com uma protuberância entre as coxas anteriores; superfície ventral do abdome apresentando pontuação igual a do resto do corpo e ausente na faixa longitudinal mediana; cabeça do parâmero com projeção anterior alongada como em E. rufomarginata; projeção posterior ausente; face externa da cabeça do parâmero sem concavidades e com uma esculturação helicoidal; processo da taça genital em forma de bastão, com a face superior escavada; décimo segmento com margem posterior não projetada, sem sulco, glabra; face posterior truncada, rugosa e com leve carena; gonocoxitos 8 decliventes, com o bordo posterior em arco semifechado, sem recorte.

Descrição. Comprimento 14,9-16,6 mm; largura 8,2-
9,6 mm, corpo ovalado. Coloração geral da face dorsal verde; margens das jugas, margens ântero-laterais do pronoto, terço anterior do cório e conexivo amareloclaros; pontuação fina freqüentemente escura. Ângulos umerais não desenvolvidos. Face ventral e pernas castanho-alaranjadas; antenas castanho-claras. Face ventral com estrias descoloridas apenas posteriormente aos espiráculos.

Cabeça mais larga que longa. Jugas mais longas que o clípeo, com pequenos sulcos transversais e sem pontuação, arredondadas e curvadas ventralmente no ápice. Tubérculos anteníferos com dente inconspícuo; antenômeros em ordem crescente de comprimento do primeiro ao quarto; quarto e quinto subiguais. Rostro atingindo a primeira bifurcação do processo do metasterno, com o primeiro segmento tão longo quanto as búculas. Búculas paralelas e largas. Pronoto declivente, brilhante, com os ângulos ântero-laterais armados com pequeno dente. Margem ântero-lateral reta, íntegra e não emarginada. Cicatrizes do pronoto subcalosas e não pontuadas. Pontuação da superfície ventral do pronoto igual a da superfície dorsal. Escutelo brilhante, com ápice levemente acuminado. Cório fosco, com pontuação igual a do resto do corpo e veias sem diferença de coloração. Membrana do hemiélitro castanho-escura a negra brilhante, sem reflexo metálico. Mesosterno sem carena mediana, com uma protuberância entre as coxas anteriores. Processo metasternal mais longo que largo, achatado, liso e glabro, apresentando a bifurcação anterior divergente e com os ápices evanescentes. Bifurcação anterior do processo metasternal atingindo o terço posterior do mesosterno e acomodando parcialmente o quarto segmento do rostro. Área evaporatória rugosa, fosca, da mesma cor que a face ventral; peritrema ostiolar atingindo $4 / 5$ da largura da metapleura. Conexivo exposto, com a pontuação clara igual a do resto da superfície dorsal. Ângulos pósterolaterais do conexivo e ângulos posteriores do sétimo segmento pouco desenvolvidos. Face dorsal do abdome castanho-escura. Superfície ventral com pontuação igual a do resto do corpo e ausente na faixa longitudinal mediana. Espiráculos elípticos e tricobótrios na mesma linha dos espiráculos.

Genitália masculina. Pigóforo retangular em vista dorsal, com abertura dorso-posterior e ângulos pósterolaterais arredondados (fig. 17); superfície ventral com pontuações e sulcos sinuosos na metade posterior e uma protuberância no meio do terço posterior. Cabeça do parâmero com projeção anterior alongada, como em $E$. rufomarginata; projeção posterior ausente. Face externa da cabeça do parâmero sem concavidades, com uma esculturação helicoidal (fig. 18). Processo da taça genital em forma de bastão e escavada superiormente (fig. 19). Décimo segmento com margem posterior não projetada, sem sulco e sem pêlos (fig. 17); face posterior truncada, rugosa e com uma leve carena.

Genitália feminina. Gonocoxitos 8 decliventes, pilosos, pontuados e posicionados num plano diferente das demais placas genitais. Bordo posterior do gonocoxito $8 \mathrm{em}$ arco semifechado e sem recorte (fig. 20). Gonocoxitos 9 fracamente convexos, muito pilosos, trapezoidais e às vezes com carena mediana presente. 
Distribuição. Brasil: Pará, Mato Grosso, Minas Gerais, Goiás e Distrito Federal.

Material examinado. "América do Sul", holótipo \&, Mr. Children's col. (BMNH). BRASIL, Pará: Gorotire, , , 14.XI.1977, D. Posey col. (MPEG); Mato Grosso: Chapada dos Guimarães, ơ, 2 \&, 19-23.I.1961, J. \& B. Bechyné col. (MPEG); đ̛, 09.II.1962, J. \& B. Bechyné col. (MPEG); (Fazenda Buriti), ơ, 2 \&, 16.XI.1982, M. Zanuto \& W. Overal col. (MPEG); Minas Gerais: Lagoa Santa, O', 05.VI.1956, \&, 13.VIII.1956 (comparado com o holótipo de A. marginalis), J. Becker col. (MNRJ); Goiás: Jataí (Fazenda Cachoeirinha), đ', I.1964, Morgante \& Silva col. (UFRG); Distrito Federal: Planaltina, \&, 28.III.1978, V. Becker col. (UFRG).

Diagnose diferencial. Edessa albomarginata e $E$. marginalis se diferenciam de E. rufomarginata por apresentarem o décimo segmento dos machos com margem posterior não projetada e o rostro com o primeiro segmento tão longo quanto as búculas.

Os machos de E. albomarginata diferenciam-se das demais espécies por apresentarem o bordo dorsal do pigóforo com duas abas que se projetam de cada lado sobre as laterais do décimo segmento, encobrindo os processos do diafragma; projeção anterior da cabeça do parâmero alongada e afilada; processo da taça genital de contorno retangular, com sutura diagonal junto ao ápice, que acompanha uma leve reentrância e outra sutura basal sem reentrância.

Edessa marginalis se distingue das outras duas espécies por apresentar o mesosterno sem carena mediana e com uma protuberância entre as coxas anteriores; cabeça do parâmero com projeção posterior ausente e com a face externa com uma esculturação helicoidal; processo da taça genital em forma de bastão, com a face superior escavada.

Os machos de E. rufomarginata podem ser diferenciados de E. albomarginata e E. marginalis por apresentarem projeção anterior da cabeça do parâmero com ápice arredondado, processo da taça genital retangular, achatado lateralmente e fendido medianamente.

Nas fêmeas as principais diferenças estão na forma dos gonocoxitos 8. Edessa albomarginata apresenta o terço posterior dos gonocoxitos 8 deprimido; bordo posterior formando um arco fechado e recortado próximo ao bordo sutural (fig. 16). Edessa marginalis possui gonocoxitos 8 decliventes, com o bordo posterior em arco semifechado, sem recorte (fig. 20). Em E. rufomarginata os gonocoxitos 8 não são deprimidos e nem decliventes e o bordo posterior é em arco aberto (fig. 4).

Notas taxonômicas. Com base no exame dos holótipos de Aceratodes albomarginatus e Aceratodes marginalis, constatou-se que são espécies diferentes de E. rufomarginata. A análise do holótipo ơ de Aceratodes discolor Dallas, 1851, Br. Guyana, R. Schomburgk col. (BMNH), evidenciou diferenças morfológicas quando comparada a E. rufomarginata. O exame da série de síntipos de Edessa abdominalis Erichson, 1848, $3 \circlearrowleft$ e $q$, British Guyana, R. Schomburgk col. (ZMHB), e do holótipo de Aceratodes discolor evidenciou pertencerem à mesma espécie. Portanto, $A$. discolor é retirada da sinonímia de E. rufomarginata e
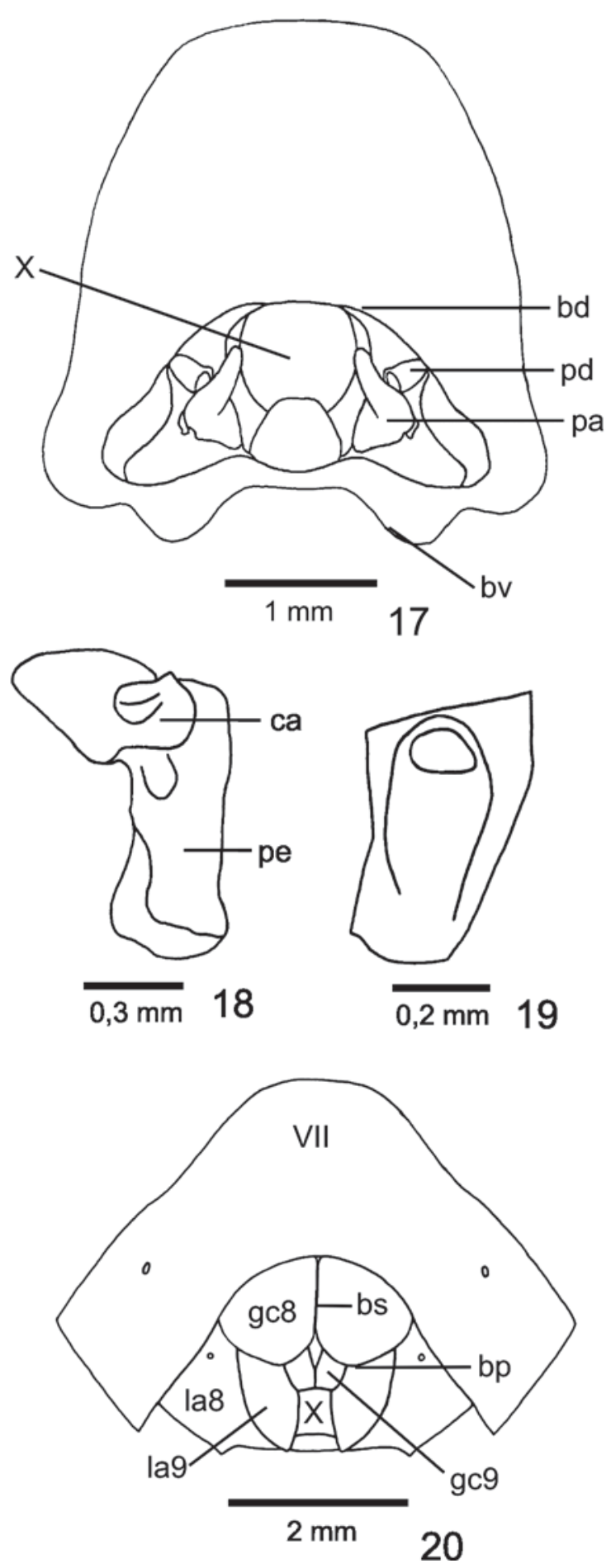

Figs. 17-20. Edessa marginalis (Dallas, 1851): 17, pigóforo, vista dorso-posterior; 18, parâmero, vista lateral externa; 19, processo da taça genital, vista lateral; 20, placas genitais, vista ventral (bd, bordo dorsal; bp, bordo posterior; bs, bordo sutural; bv, bordo ventral; ca, cabeça; gc8, gonocoxito 8; gc9, gonocoxitos 9; la8, laterotergito 8; la9, laterotergito 9; pa, parâmero; pd, processo da taça genital; pe, pé; VII, $7^{\circ}$ segmento abdominal; X, $10^{\circ}$ segmento abdominal).

considerada sinônimo júnior de Edessa abdominalis Erichson, 1848.

Agradecimentos. Aos curadores das coleções, Dr. Sérgio 
Ide (IBSP), Édson P. Teixeira (IACC), Axel O. Bachmann (MACN), Nair O. Aguiar (DCMB) e Dr. José A. Rafael (INPA), pelo empréstimo dos exemplares. Aos curadores Dr. Mick Webb (BMNH) e Dr. Bert Viklund (NHRM) por permitir o exame dos tipos.

\section{REFERÊNCIAS BIBLIOGRÁFICAS}

Амyot, C. J. B. \& Serville, A. 1843. Histoire naturelle des Insectes. Hémiptères. Paris, Libraire Encyclopédique de Roret. 681p., 12 est.

Bertels, A. M. 1962. Insetos - hóspedes de Solanáceas. Iheringia, Série Zoologia, Porto Alegre, (25):1-12.

Biezanko, C. M.; Bertholdi, R. E. \& Baucke, O. 1949. Relação dos principais insetos prejudiciais observados nos arredores de Pelotas nas plantas cultivadas e selvagens. Agros, Pelotas, 2:156-213.

Buckup, L. 1961. Os pentatomídeos do Estado do Rio Grande do Sul (Brasil) Hemiptera-Heteroptera-Pentatomidae. Iheringia, Série Zoologia, Porto Alegre, (16):1-24.

Burmeister, H. 1835. Handbuch der entomologie. Berlin, T. Enslin. v.1, 400p.

Dallas, W. L. 1851. List of the specimens of Hemipterorus insects in the collection of the British Museum. Part I. London, The Trustees. 390p.

De Geer, C. 1773. Memoires pour servir a l'historie des insectes. Tome Troisieme. Stockholm, Pierre Hesselberg. $696 \mathrm{p}$.

Distant, W. L. 1880-1883. Biologia Centrali-Americana. Rhynchota. Hemiptera-Heteroptera. London, Godman \& Salvin. v.1, 462p.

Dupuis, C. 1970. Heteroptera. In: Tuxen, S. L. ed. Taxonomist's Glossary of genitalia of insects. Copenhagen, Munskgaard. p.190-208.

Fabricius, J. C. 1775. Systema entomologiae, sistens insectorum classes, ordines, genera, species, adjectis synonymis, locis, descriptionibus, observationibus. Lipsiae, Officina Libraria Kortii. 832p.

1803. Systema rhyngotorum secundum ordines, genera, species, adjectis synonymis, locis, observationibus, descriptionibus. Brunsvigae, Carolum Reichard. 314p.

Fortes, N. D. F. \& Grazia, J. 1990. Estudo dos estágios imaturos de Edessa rufomarginata (De Geer, 1773) (Heteroptera - Pentatomidae). Anais da Sociedade Entomológica do Brasil, Porto Alegre, 19(1):191-200.

Froeschner, R. C. 1981. Heteroptera or true bugs of Ecuador: a partial catalog. Smithsonian Contributions to Zoology, Washington, 322:1-147.

Grazia-Vieira, J. \& Casini, C. E. 1973. Lista preliminar dos heterópteros uruguaios da região nordeste: Pentatomidae e Coreidae (Insecta; Heteroptera). Iheringia, Série Zoologia, Porto Alegre, (44):55-63.

Kirkaldy, G. W. 1909. Catalogue of Hemiptera (Heteroptera). 1. Cimicidae. Berlin, Felix L. Dames. $392 p$.

Lethierry, L. \& Severin, G. 1893. Catalogue Général des Hémiptères. Tome I. Hétéroptères Pentatomidae. Bruxelas, F. Hayez. 286p.

Monte, O. 1939. Hemípteros fitófagos. O Campo, Belo Horizonte, 8:58-61.

Palisot De Beauvois, A. M. F. J. 1805. Insectes recuillis en Afrique et en Amérique dans les royaumes D'Oware et de Benin, a Santi-Domingue et dans les ÉtatsUnis, pendant les années 1786-1797. Paris, Fain et Compagnie. 267p.

Rizzo, H. F. \& SaINI, E. D. 1987. Aspectos morfologicos y biologicos de Edessa rufomarginata (De Geer) (Hemiptera, Pentatomidae). Revista de la Facultad de Agronomía, Buenos Aires, 8(1-2):51-63.

Ruffinelli, A. \& Carbonel, C. S. 1953. Segunda lista de insectos y otros artropodos de importancia economica en el Uruguai. Revista de la Asociación de Ingenieros Agrónomos, Montevideo, (9):33-82.

SHARP, D. 1890. On the structure of the terminal segment in some male Hemiptera. The Transctions of the Entomological Society of London, London, (3):399-427.

Silva, A. G. D. A.; Gonçalves, C. R. et al. 1968. Quarto catálogo dos insetos que vivem nas plantas do Brasil, seus parasitos e predadores. Parte II - Insetos, hospedeiros e inimigos naturais. Rio de Janeiro, Ministério da Agricultura. v.1, 622p.

STÅL, C. 1855. Kya Hemiptera. Öfversigt af Kongliga Vetenskaps-Akademiens Förhandlingar, Stockholm, 12(4):181-192.

1872. Enumeratio Hemipterorum. Bildrag till em förteckning öfver alla hittilis Hemiptera, jemte systematiska meddelanden. 2. Bihang till Kongliga Svenska Vetenskaps-Akademiens Handlingar, Stockholm, 10(4):1-159.

Stoll, C. 1788. Représentation exactement colorée d'après nature des Punaises, qui se trouvent dans les quatre parties du monde, l'Europe, l'Asie, l'Afrique et l'Amérique rassemblées et décrites. Amsterdam, Jan Christiaan Sepp. 172p.

Walker, F. 1867. Catalogue of the specimens of Heteropterous-Hemiptera in the collection of the British Museum. London, British Museum. Parts 1-3, 599p. 